\title{
Efeito da Suplementação com Óleo de Peixe no Modelo Experimental de Sepse
}

\author{
Renata Campos ${ }^{1}$, Andressa Antunes Bortoti ${ }^{2}$, Chelin Auswaldt Steclan ${ }^{2}$, \\ Pollyana Weber da Maia Pawlowytsch'2, Miriam Cristina José Valério², \\ Cinthia Helena Paluch ${ }^{2}$, Luiz Cláudio Fernandes ${ }^{3}$
}

\section{RESUMO}

Objetivo: Investigar o efeito da suplementação com óleo de peixe (OP), rico em ácido graxo ômega-3, sobre as variáveis renal e pulmonar, a mortalidade e a lipoperoxidação em ratos com sepse. Método: A sepse foi induzida por punção e ligadura cecal (CLP). OP (1 g/kg/dia, via oral) foi administrado sete dias antes da CLP. Foram estudados os grupos CLP (CLP sem OP, n=10) e CLP+OP (suplementado com OP, $n=10)$. Foram mensurados a peroxidação lipídica, a histologia pulmonar e renal, quanto à sua estrutura e presença de polimorfinucleares (PMN), índice de edema pulmonar, função renal e sobrevida em 72 horas. Resultados: A peroxidação lipídica não foi diferente para o grupo $C L P+O P(p=0,06)$. A histologia, quanto à estrutura, evidenciou que o grupo CLP+OP teve menor lesão estrutural tanto no tecido pulmonar quanto no renal, entretanto a contagem de PMN não foi diferente entre os grupos para ambos os sistemas. O índice de edema pulmonar, embora menor no grupo $\mathrm{CLP}+\mathrm{OP}$, não foi significativamente diferente do encontrado no grupo $\mathrm{CLP}(\mathrm{p}=0,59)$. Não houve alterações quanto à melhora da sobrevivência causada pela suplementação com OP. A função renal, estudada pela concentração de ureia e pela creatinina, não foi diferente entre os grupos. Conclusão: A suplementação com OP, na dose e tempos empregados, não provocou efeitos positivos nas variáveis renais, pulmonares e taxa de mortalidade de ratos com sepse.

Palavras-chave: Sepse. Mortalidade. Ácidos graxos. Peroxidação de lipídios. Sistema imunitário. Edema pulmonar.

\section{EFFECT OF FISH OIL SUPPLEMENTATION ON SEPSE}

\section{ABSTRACT}

Objective: To investigate the effect of supplementation with fish oil (FO) rich in omega-3 fatty acids, on renal and pulmonary variables, mortality and, lipid peroxidation in rats with sepsis. Methods: Sepsis was induced by puncture and cecal ligation (CLP). FO (1 g/kg/day, orally) was given for seven days before CLP. CLP groups (CLP without FO, $n=10$ ) and CLP+FO (supplemented with FO, $n=10$ ) were studied. The variables lipid peroxidation, lung and renal histology were analyzed regarding its structure and presence of polymorphonuclear (PMN), lung edema index, renal function and survival rate. Results: The lipid peroxidation was not different for $\mathrm{CLP}+\mathrm{FO}$ group $(\mathrm{p}=0.06)$. Histology, regarding structure, the $\mathrm{CLP}+\mathrm{FO}$ group had lower structural damage, both in the lung and kidney tissues, however, the PMN cells counting was not different between the groups, for both systems. The rate of lung edema, although lower in the CLP+FO group, was not significantly different from that found in the CLP group ( $p=0.59)$. FO supplementation did not cause any change in the survival rate $(p>0.05)$. Renal function, studied by urea and creatinine concentration was not different between the groups $(p>0.05)$. Conclusion: FO supplementation, in the dose and period studied, did not improve renal, pulmonary and mortality rate in rats with sepsis.

Keywords: Sepsis. Mortality. Fatty acids. Lipid peroxidation. Immunitary system. Lung edema.

RECEBIDO EM: 25/3/2019

MODIFICAÇÕES SOLICITADAS EM: 8/10/2019

ACEITO EM: 11/11/2019

\footnotetext{
${ }^{1}$ Autora correspondente. Universidade do Contestado - Campus Mafra. Av. Nereu Ramos, 1071, ala das coordenações/Nupesc, Jardim Moinho. Cep: 89300-000, Mafra/SC, Brasil. http://lattes.cnpq.br/1087923612231555. https://orcid.org/0000-0002-8018-6209. replug2000@gmail.com

2 Universidade do Contestado. Campus Mafra. Mafra/SC, Brasil.

${ }^{3}$ Universidade Federal do Paraná. Curitiba/PR, Brasil.
} 


\section{INTRODUÇÃO}

O ácido graxo poli-insaturado (Agpi) alfa linolênico ômega $3(\omega-3)$ é um ácido graxo essencial que não pode ser produzido pelo organismo humano (DUVALL; LEVY, 2016). Os Agpis $\omega$-3 são encontrados primariamente em óleos de peixe (OP) e em plantas de coloração verde escura, e seus metabólitos são capazes de reduzir ou minimizar a criticidade de algumas patologias, como as cardiovasculares (MANZANARES; LANGLOIS; HARDY, 2016).

Os dois principais componentes do OP são os ácidos graxos eicosapentaenoico (EPA, 20:5 $\omega$-3) e docosahexaenoico (DHA, 22:6 $\omega-3)$, que têm ação sobre a fluidez de membrana celular, regulam a função imunitária, diminuem a excessiva reação inflamatória, reduzem a ocorrência da Síndrome da Resposta Inflamatória Sistêmica (Sirs) e a disfunção múltipla de órgãos (ZHAO; WANG, 2018).

Durante a sepse, as vias pró-inflamatórias aumentam suas atividades para eliminar patógenos e tecidos mortos, frequentemente causando lesão ao hospedeiro. Há, entretanto, uma relação positiva entre o consumo de OP e a melhora nas condições anti-inflamatórias (BAKER et al., 2016). A resolução do processo inflamatório inclui a inibição do infiltrado tecidual, regulação da produção e secreção das citocinas e quimiocinas, redução da dor e a ação dos macrófagos, o que pode ser fundamental no quadro da sepse (SERHAN; CHIANG, 2013).

A suplementação com OP altera a expressão e a produção das citocinas pró-inflamatórias e fornece modificações na modulação da resposta inflamatória, com mínimos efeitos colaterais (SERHAN, 2014). Em adição, pode afetar a função imunitária e estar associado com melhor resultado e redução nos custos de saúde em pacientes cirúrgicos e criticamente doentes. Há, ainda, contudo, controvérsias na indicação para pacientes em unidades de terapia intensiva (MOLFINO et al., 2017). $\mathrm{O}$ uso de OP, via parenteral, em pacientes internados no período pós-operatório, foi considerado seguro e efetivo na redução da permanência em UTI, minimizando a taxa de mortalidade (PRADELLI et al., 2012).

A capacidade anti-inflamatória do OP inclui a inibição da migração de neutrófilos, o aumento da fagocitose de neutrófilos em apoptose e a supressão de citocinas pró-inflamatórias e quimiocinas, particularmente durante a doença aguda (DUVALL; LEVY, 2016). Também diminui a aderência e migração de neutrófilos e aumenta a velocidade em vênulas pós-capilares. Ainda, o OP altera os monócitos no sítio de inflamação, o que indica forte evidência do clearance apoptótico dos polimorfinucleares (PMN) em animais com sepse (KÖRNER et al., 2018).
Evidências demonstram que a redução do processo inflamatório com o uso da combinação de OP e de ácido graxo de cadeia curta de ômega- 6 foi efetiva para reduzir o tempo de ventilação e o tempo de hospitalização, além de aumentar a sobrevivência global (SINGER et al., 2006). Ying-Hua et al. (2015) usaram lipopolissacarídeos para induzir o modelo de sepse e relataram drástico aumento nas concentrações de interleucinas (IL) como a IL-1 $\beta$, IL- 6 e o fator- $\alpha$ de necrose tumoral (TNF- $\alpha$ ), tanto no plasma quanto no intestino. Ao administrarem OP, entretanto, encontraram diminuição significativa das concentrações de citocinas, bem como da expressão de mRNA de IL-1 $1 \beta$, IL-6 e TNF- $\alpha$ em uma pequena porção do intestino.

Em um processo inflamatório e infeccioso ocorre desequilíbrio entre a produção de espécies reativas de oxigênio (Eros) e a de antioxidantes. A diferença entre as espécies reativas de oxigênio nos compartimentos teciduais e subcelulares contribui para a resposta ao estresse (GO et al., 2010). Vários fatores são responsáveis pelos Eros; na sepse cita-se o aumento das toxinas urêmicas associado à disfunção celular endotelial (YANG et al., 2012).

Evidências mostram que o OP tem efeitos antioxidantes por modular o sinal redox, aumentando a expressão e as atividades das enzimas antioxidantes, e atenuando o dano oxidativo (ERDOGAN et al., 2004). Desta forma, acredita-se que o OP pode ser considerado modulador participante da regulação do início, da duração e da resolução da inflamação, e ser efetivo em respostas inflamatórias não controladas.

A sepse é uma síndrome com elevada morbidade/mortalidade em pacientes criticamente doentes, e apresenta alto custo de tratamento. $O$ reconhecimento de terapias adjuvantes, portanto, é fundamental para a mudança do cenário causado pela sepse. Desta forma, o uso de terapias alternativas tem sido buscado, e, por se tratar de processo inflamatório, o e prego de OP configura uma boa alternativa. Sendo assim, o presente estudo investigou o efeito da suplementação com OP durante sete dias anteriores à ligadura cecal, sobre as variáveis renal e pulmonar, mortalidade e a peroxidação lipídica em ratos com sepse induzida por punção de ligadura cecal (CLP).

\section{MÉTODOS}

Este estudo foi conduzido no laboratório de Fisiologia do Departamento de Ciências Biológicas da Universidade Federal do Paraná, mediante aprovação da Comissão de Ética no Uso de Animais (Ceua), sob parecer $\mathrm{n}$ - 1.094 . 
Animais e protocolo de suplementação

Foram utilizados ratos machos Wistar (45 dias de idade com peso entre 200 a $250 \mathrm{~g}$ ), suplementados ou não, com OP na dose de $1 \mathrm{~g} / \mathrm{kg}$, diariamente, iniciando-se sete dias antes da punção e CLP, e mantendo-se até o dia da CLP. O OP foi administrado via oral, com o auxílio de micropipeta em que, pela ponteira, o OP era gotejado na boca do animal até a completa deglutição.

Os grupos foram divididos em G1: CLP (submetido à $C L P$, sem $O P ; n=10) ; G 2$ : $C L P+$ suplementação com OP $(n=10)$. Para avaliação da taxa de sobrevida foram utilizados animais diferentes ( $n=5$ para cada grupo), sendo usados somente para esta finalidade.

\section{Punção e ligadura cecal}

Os animais foram anestesiados via intraperitoneal (i.p.) com cloridrato de cetamina e xilazina. Após tricotomia da região abdominal e laparotomia, o ceco foi exposto e ligado abaixo da válvula ileocecal, sendo puncionadas duas vezes (agulha 16) e levemente pressionado a expelir pequena quantidade de material fecal na cavidade abdominal (MIYAJ et al., 2003). Após o procedimento foi realizada a sutura por planos na incisão abdominal. Todos os procedimentos cirúrgicos foram realizados por um único pesquisador.

Após a realização da CLP foi administrado cloreto de sódio $0,9 \%$ na dose de $25 \mathrm{ml} / \mathrm{kg}$ (i.p.) para manutenção de volemia. A reposição volêmica foi administrada 6 e 12 horas após a CLP via subcutânea (sc), assim como o antibiótico Meropenem, na dose de 30 $\mathrm{mg} / \mathrm{kg}(\mathrm{sc}$ ) após 6 e 12 horas da realização da sepse. Também foi administrada Dipirona injetável $(500 \mathrm{mg}$ / $\mathrm{kg}$ ) para a dor (sc). As dosagens do antibiótico e a reposição volêmica e do analgésico foram padronizadas pelo médico veterinário que acompanhou todo o processo.

Após 24 horas da CLP, todas as avaliações do sistema renal e respiratório foram realizadas.

\section{Contagem de células polimorfonucleares no tecido pulmonar e renal}

Morfometria convencional foi utilizada para determinar a densidade dos neutrófilos PMN. As lâminas coradas com Hematoxilina-Eosina (HE) foram avaliadas por microscopia óptica em uma resolução de 100X. Após a visualização, foi realizada a contagem dos PMNs, a partir das áreas delimitadas por retículo (VIEIRA et al., 2007). Foram analisados 16 campos por lâmina.
O examinador não teve prévio conhecimento dos grupos durante a análise das lâminas, garantindo uma análise não tendenciosa durante a contagem das células.

\section{Relação peso úmido e peso seco do pulmão}

Fragmentos do pulmão foram retirados da caixa torácica, lavados superficialmente com soro fisiológicos e secos para retirada de quaisquer resíduos. 0 tecido pulmonar foi pesado (peso úmido), colocado em um recipiente de vidro e deixado na estufa a $60{ }^{\circ} \mathrm{C}$ por 48h. Passado este período, o pulmão foi novamente pesado (peso seco) e obteve-se a relação peso úmido e peso seco (W/D) (CAMPOS et al., 2012).

\section{Dosagem de ureia e creatinina}

Amostra sanguínea foi coletada 24 horas por punção intracardíaca após a CLP, para a avaliação dos marcadores renais. As amostras foram coletadas e colocadas em tubos comerciais padrões, contendo EDTA, e a concentração de ureia e creatinina foram determinadas por kits da Elitech, seguindo-se as instruções do fabricante.

\section{Mensuração da lipoperoxidação}

A solução FOX-2 foi preparada conforme o procedimento descrito por Nourooz-Zadeh (1999). Alíquotas de $90 \mu \mathrm{l}$ de plasma foram adicionadas em quatro tubos de ensaio, e $10 \mu$ de Trifenilfosfina (TPP) em metanol $10 \mathrm{mM}$ foram acrescidos em cada tubo. Em outros quatro tubos de ensaio foram adicionados às alíquotas de $90 \mu \mathrm{l}$ de plasma e $10 \mu \mathrm{l}$ de metanol. Essas amostras foram incubadas por 30 minutos, após agitação no vórtex. Em seguida, $900 \mu \mathrm{l}$ de FOX-2 foram acrescentados a cada tubo de ensaio, e as amostras foram novamente incubadas por mais 30 minutos. A solução FOX-2, em contato com peróxidos, altera sua coloração de amarelo para azul. Então, foram centrifugadas por dez minutos e submetidas à leitura no espectrofotômetro no comprimento de onda de 560 $\mathrm{nm}$. Para a curva de calibração, foram adicionadas em tubos de ensaio diferentes concentrações de peróxido de hidrogênio $\left(\mathrm{H}_{2} \mathrm{O}_{2}\right)$ e $900 \mu$ le FOX-2. Em seguida foi feita a leitura no espectrofotômetro a $560 \mathrm{~nm}$. As concentrações usadas de $\mathrm{H}_{2} \mathrm{O}_{2}$ foram: 4; 4,6; 5; e 6 $\mu \mathrm{mol} / \mathrm{L}$.

O coeficiente de absortividade molar é de $3.92 \times 10^{-4} \mathrm{~mol} \mathrm{~L}^{-1} \mathrm{~cm}^{-1}$. Para melhor confiabilidade da curva analítica, $\mathrm{O}_{2} \mathrm{O}_{2}$ utilizado foi padronizado por titulação redox em triplicata, usando $\mathrm{KMnO}_{4}$ padronizado com ácido oxálico. 


\section{Taxa de sobrevivência}

Para a análise da taxa de sobrevida os animais ( $n=5$ para cada grupo) foram mantidos em gaiolas com livre-acesso à comida e água, e acompanhados por 72 horas após a CLP (durante este período não houve a suplementação de OP). A avaliação aconteceu às 7 horas, 13 horas e 19 horas de cada dia.

Nos animais CLP e CLP+OP foram administrados Meropenem (30 mg/ $\mathrm{kg}$ ) e soro fisiológico $(25 \mathrm{ml} / \mathrm{kg}$ ) a cada 12 horas, às 7 horas e às 19 horas de cada dia. 0 analgésico Dipirona injetável ( $500 \mathrm{mg} / \mathrm{kg}$ - via sc) foi administrado de seis em seis horas.

Após as 72 horas de acompanhamento, os animais remanescentes foram sedados e mortos com cloreto de potássio $10 \%$.

\section{Análise estatística}

Os dados estão apresentados em média \pm desvio padrão. As comparações entre médias foram realizadas pelo teste Mann-Whitney. A curva de sobrevivência foi realizada pelo teste Kaplan-Meier. Aceitou-se como nível de significância p<0,05.

\section{RESULTADOS}

O primeiro dado apresentado é o de inflamação tecidual, tanto no tecido pulmonar quanto no renal, estudado pela presença de neutrófilos PMN. No sistema pulmonar a quantificação de PMN foi de $4,86 \pm 2,34$ células $/ \mathrm{mm}^{2}$ para o grupo CLP e 4,63 $\pm 2,11$ células $/ \mathrm{mm}^{2}$ para o grupo $C L P+O P, p=0,54$. Para o sistema renal obteve-se $7,13 \pm 2,04$ células $/ \mathrm{mm}^{2}$ para o grupo CLP e $6,53 \pm 1,98$ células $/ \mathrm{mm}^{2}$ para o grupo CL$\mathrm{P}+\mathrm{OP}, \mathrm{p}=0,55$ (Figuras $1 \mathrm{a}$ e $1 \mathrm{~b}$, respectivamente).

Figura 1 - Presença de células PMN nos pulmões (A) e rins (B) de animais do grupo CLP e CLP+OP. Os dados estão apresentados como células $/ \mathrm{mm}^{2}$

$1 \mathrm{~A}$ - Polimorfinuclear no tecido pulmonar

\section{Polimorfinucleares - Tecido Pulmonar}

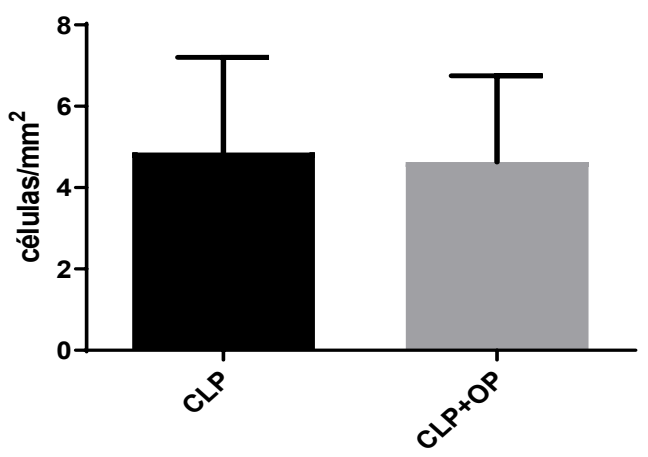

Fonte: Os Autores (2018).

\section{B - Polimorfinuclear no tecido renal}

\section{Polimorfinucleares - Tecido Renal}

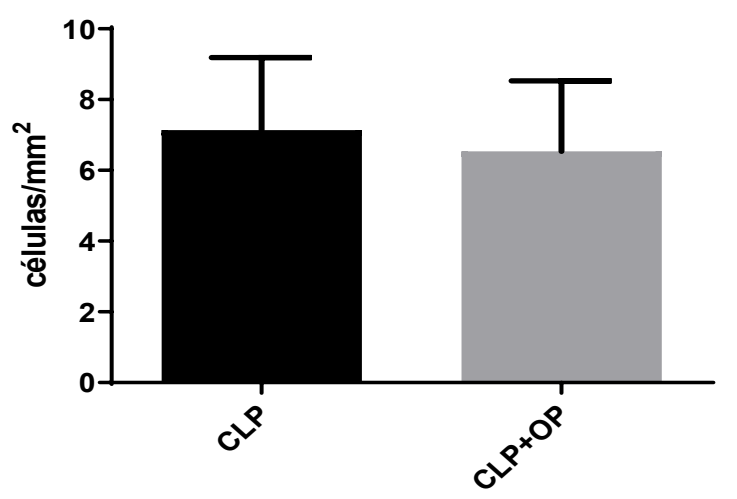

Fonte: Os Autores (2018).

Na histologia pulmonar e renal observam-se algumas características importantes em ambos os grupos. A estrutura pulmonar do grupo CLP+OP apresentou menor número de lesões quando comparada ao grupo CLP (Figuras 2A e 2B, respectivamente). O mesmo foi observado no tecido renal, quando a suplementação com OP também provocou menor lesão no grupo suplementado (Figuras $2 \mathrm{C}$ e $2 \mathrm{D}$, respectivamente).

Figura 2 - Histologia do tecido pulmonar e renal dos animais dos grupos CLP (B e D) e suplementados com $\mathrm{OP}$ ( $\mathrm{A}$ e $\mathrm{C}$, respectivamente)

A (ômega): área pulmonar pérvia, com menor espessamento de tecido.

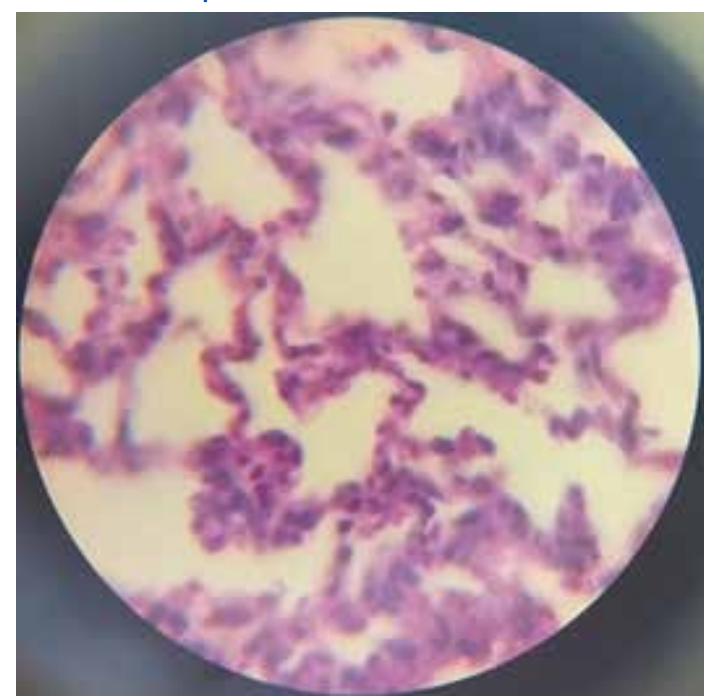


B (CLP): Espessamento de tecido com infiltração tecidual pulmonar.

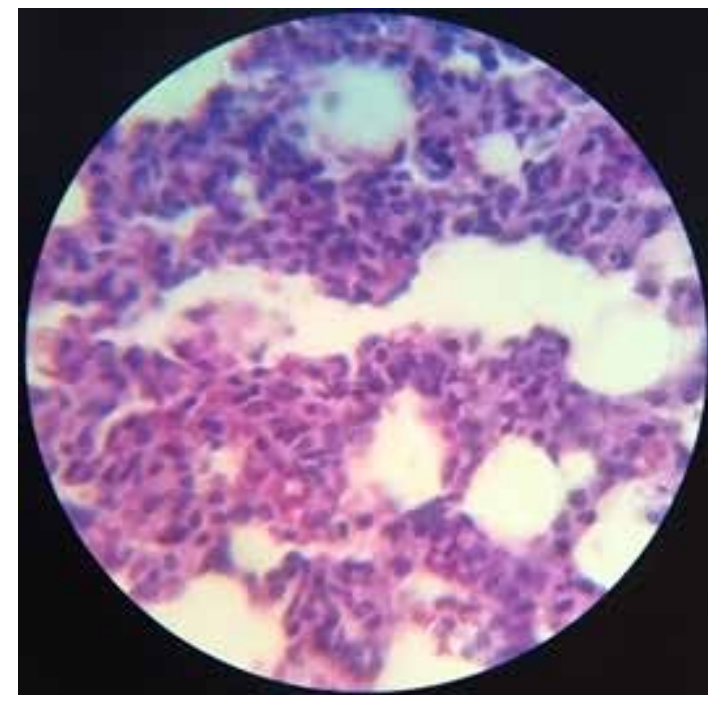

C (ômega): área renal (túbulos) preservada.

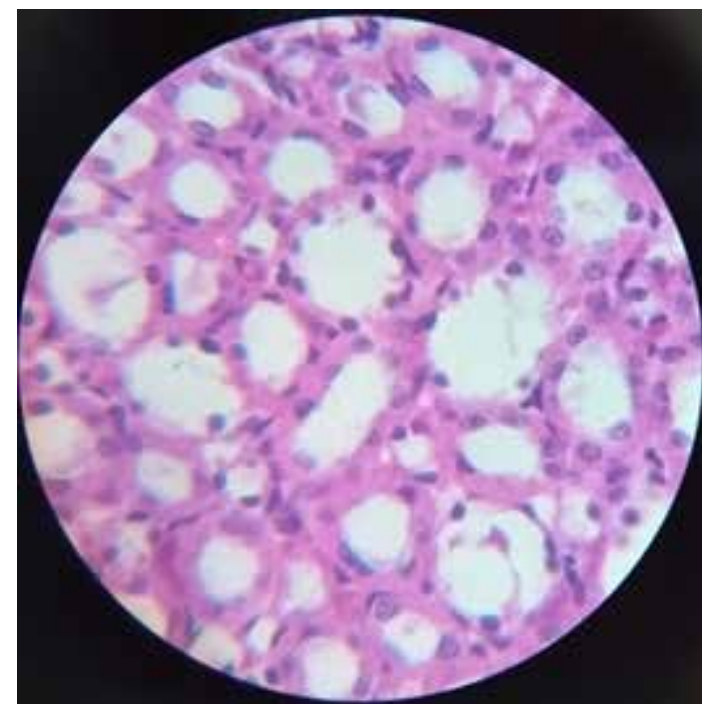

D (CLP): influxo celular e espessamento dos túbulos

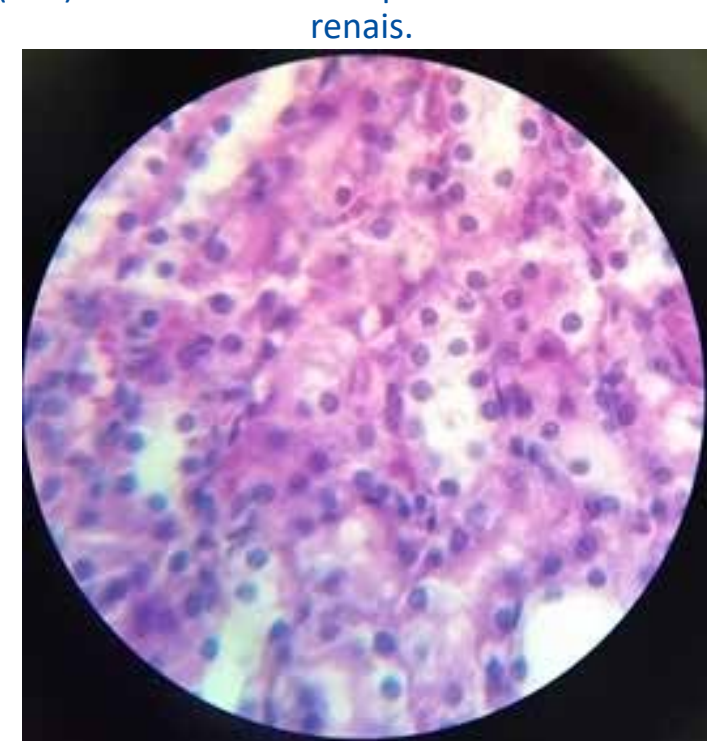

Fonte: Os Autores (2018).
A relação peso úmido e peso seco (Figura 3) não mostrou diferença entre os grupos estudados, embora o grupo suplementado com OP tenha valores inferiores $\left(4,74 \pm 0,71 \mathrm{H}_{2} \mathrm{O} / \mathrm{g}\right)$ quando comparado ao $\operatorname{CLP}(5,11 \pm 0,78$ $\mathrm{H}_{2} \mathrm{O} / \mathrm{g}, \mathrm{p}=0.59$ ), mas não houve diferença estatística.

Figura 3 - Relação peso úmido e peso seco nos animais do grupo CLP e suplementados com OP

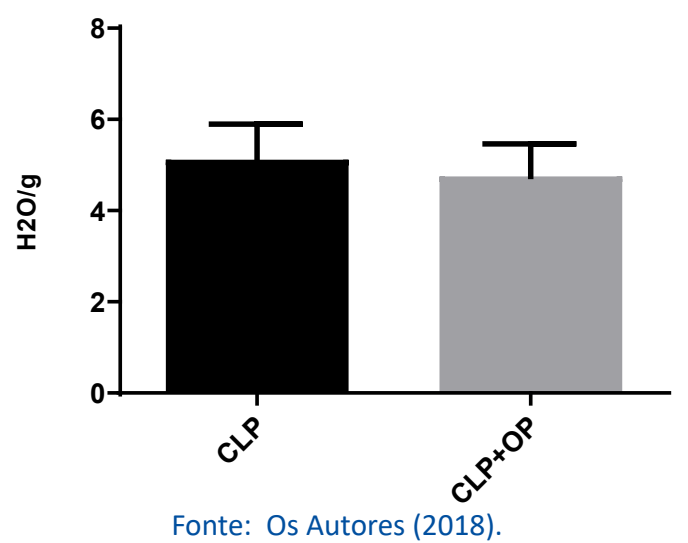

Em relação aos marcadores renais (Figura 4A), observou-se que não houve diferença nos níveis de ureia no grupo $\operatorname{CLP}(32,6 \pm 16,8 \mathrm{mg} / \mathrm{dl})$ e no $\mathrm{CLP}+\mathrm{OP}$ $(41,00 \pm 26,87 \mathrm{mg} / \mathrm{dl}, \mathrm{p}=0,42$ - Figura $4 \mathrm{~A})$. Já a concentração de creatinina (Figura $4 \mathrm{~B}$ ) foi similar entre os grupos (CLP+OP $0,48 \pm 0,15 \mathrm{mg} / \mathrm{dl}$ e para o CLP $0,59 \pm 0,15 \mathrm{mg} / \mathrm{dl}, \mathrm{p}=0,29$ ).

Figura 4 - Concentração plasmática de ureia (4A) e de creatinina (4B) dos animais do grupo CLP e dos suplementados com OP Ureia

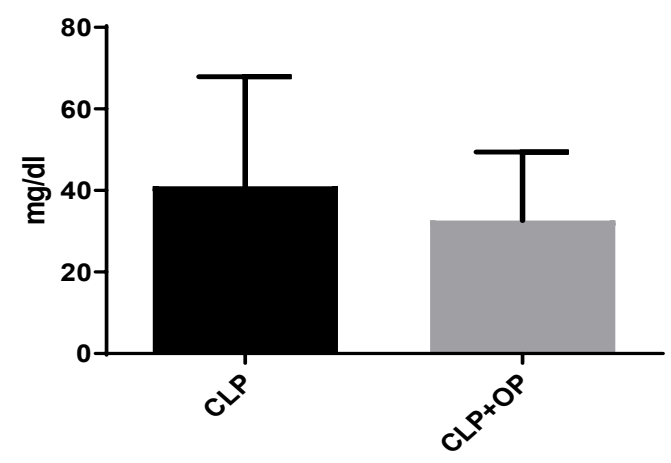

Creatinina

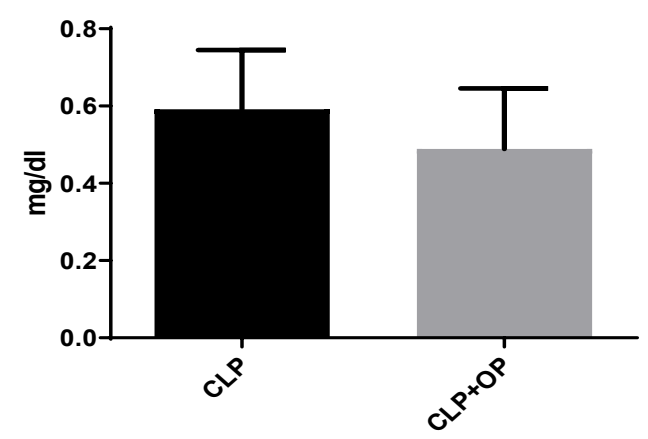

Fonte: Os Autores (2018). 
Em relação à peroxidação lipídica plasmática (Figura 5) não houve diferença entre os grupos CL$\mathrm{P}+\mathrm{OP}(0,15 \pm 0.02 \mu \mathrm{mol} / \mathrm{L})$ e $\mathrm{CLP}(0.11 \pm 0.02 \mu \mathrm{mol} / \mathrm{L})$.

Figura 5 - Peroxidação lipídica plasmática obtida dos animais do grupo CLP e CLP suplementados com OP

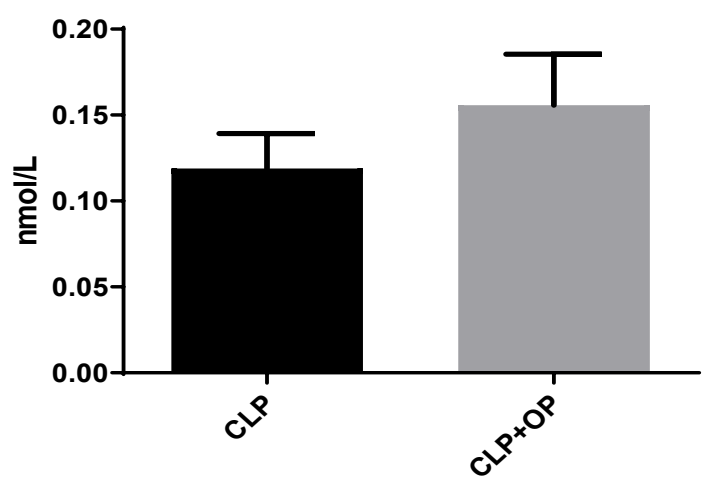

Fonte: Os Autores (2018).

Todos os animais sobreviveram nas primeiras 24 horas após a CLP. A sobrevida destes (Figura 6) não foi modificada pela suplementação com OP.

Figura 6 - Sobrevivência avaliada no 1으, 2ㅇe e 3ㅇ dias. Para cada grupo foram avaliados 5 animais

Proporção de Sobrevida

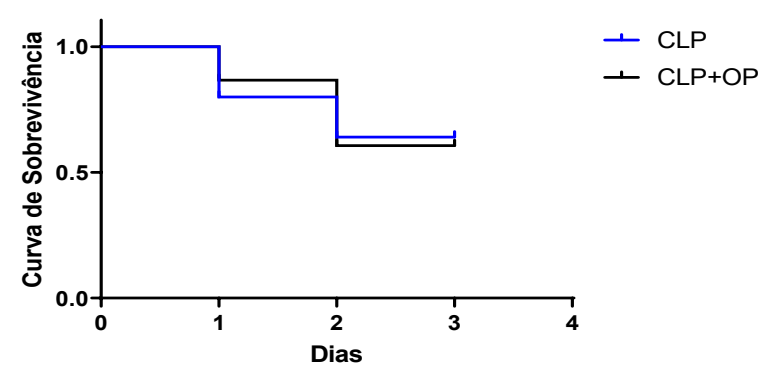

Fonte: Os Autores (2018).

\section{DISCUSSÃO}

O Agpi $\omega-3$ tem sido descrito como atuante no processo inflamatório por afetar o metabolismo dos eicosanoides de diversas maneiras. $O$ consumo de DHA e EPA resulta em aumento de suas concentrações nas membranas celulares, substituindo o ácido araquidônico (AA) nos fosfolípides de membrana, reduzindo, dessa forma, a produção de eicosanoides pró-inflamatórios derivados do $A A$, exercendo importante papel de resolução e reparo no processo de inflamação (MARANGONI et al., 1993).

A Sepse é uma síndrome que causa alta mortalidade em pacientes. Ela causa lesão pulmonar aguda caracterizada por hipoxemia e infiltrados pulmonares, além da disfunção endotelial capilar e alveolar, resultando na ativação da cascata inflamatória, elevan- do a concentração plasmática de fator- $\alpha$ de necrose tumoral (TNF- $\alpha$ ), interleucinas $1 \beta$ e IL- 6 , juntamente com a presença de macrófagos, mocócitos e neutrófilos (MARTIN; STAPLETON, 2010). Apesar de todas as evidências encontradas na literatura sobre a ação dos Agpis $\omega-3$ na minimização dos efeitos inflamatórios, o presente estudo verificou que a suplementação com OP não foi capaz de minimizar a quantidade de infiltração de PMN, tanto no tecido pulmonar quanto no renal. Interessantemente, contudo, na histologia encontrou-se menor lesão estrutural no grupo que foi suplementado com OP. Strandberg et al. (2009) descreveram que o sistema imunitário de camundongos foi negativamente afetado pela dieta rica em Agpi. A resposta imunológica pela ativação de neutrófilos é a primeira linha de defesa contra doenças bacterianas infecciosas. Moléculas derivadas de Agpi $\omega-3$, conhecidas como resolvinas, têm melhorado a capacidade do neutrófilo para fagocitar Escherichia Coli (SPITE et al., 2009). Não é, portanto, somente a quantidade de neutrófilo disponível, mas é necessário que a capacidade de fagocitose também esteja preservada. A baixa atividade do sistema imunitário, associada à proliferação bacteriana, leva ao óbito na sepse (SVAHN et al., 2016).

A lesão pulmonar também está associada à sepse. A suplementação com OP em ratos, cinco dias após a CLP, diminuiu o escore de lesão pulmonar, meIhorou a histopatologia, modulou a imunidade e reduziu o processo inflamatório (Ll et al., 2015). Campos et al. (2012) descreveram que a CLP em roedores foi capaz de aumentar o índice de edema e a relação peso úmido/seco. Um estudo com roedores descreveu que o $\mathrm{OP}$, embora tenha efeitos antioxidantes, piorou a disfunção vascular induzida pelo choque séptico (BOISRAMÉ et al., 2016). O presente estudo corrobora esses dados, posto que não foi possível determinar melhora na relação peso úmido e peso seco como um fator de aprimoramento da permeabilidade vascular.

Outra possível explicação entre os achados deste estudo e os demais da literatura parece ser o tempo de tratamento com OP no modelo CLP. Um estudo com 28 dias de tratamento melhorou a sobrevivência em camundongos com sepse induzida por Staphylococus (SVAHN et al., 2016). Aqui, foi administrado OP oralmente por sete dias antes do início da CLP, ou seja, de forma preventiva, entretanto este tempo não provocou modificação significativa na taxa de mortalidade quando comparada à do grupo CLP ao final de três dias. 
A administração de OP tem sido estudada em modelos de ablação renal, nos quais os resultados são promissores e suportam a hipótese de que OP, rico em Agpi $\omega-3$, tem ação protetora em ratos submetidos à ablação renal, e previne a evolução da glomeruloesclerose e a piora da função renal, levando à preservação da filtração glomerular (CLARK et al., 1991). Estudo em camundongos submetidos à CLP verificou que a administração de OP não causou aumento da ureia nitrogenada, que é marcador da função renal. Em adição, relatam que o escore de lesão renal avaliado pela histologia foi menor no grupo suplementado com OP (JUEY-MING et al., 2016). Miyaji et al. (2003) demonstraram que a CLP causa um aumento tempo-dependente dos marcadores renais. No presente estudo, as medidas plasmáticas foram realizadas 24 horas após a CLP, o que pode ter contribuído para o não aumento das escorias nitrogenadas.

Apesar de todos os esforços para minimizar os efeitos da sepse, a taxa de mortalidade ainda permanece alta, com valores aproximadamente entre $40 \%$ a 70\% (ALAVI et al., 2017). Existem evidências de que os Agpis $\omega-3$ podem diminuir a mortalidade associada à sepse. Isto, contudo, ainda é objeto de controvérsia. Em recente artigo de revisão (HUAl et al., 2018), foi efetuada uma análise de correlação entre administração de Agpi $\omega-3$ e a mortalidade causada pela sepse. Os autores, após análise criteriosa de estudos randomizados e controlados, descreveram que a mortalidade não foi diferente para os grupos em que foi administrado Agpi $\omega-3$. Diversos fatores foram levantados para esta afirmação, posto que a concentração de Agpi $\omega-3$, a duração do tratamento e os métodos de suporte nutricional foram diferentes entre os vários estudos.

Um dos fatores que podem influenciar na criticidade da doença é a liberação de radicais livres decorrentes do processo inflamatório e infeccioso instalado em razão da sepse. O Agpi $\omega-3$, por modular a ativação dos genes envolvidos no processo inflamatório nas células imunitárias, pode reduzir a produção de citocinas pró-inflamatórias, bem como de espécies reativas de oxigênio (BOISRAMÉ et al., 2016). Esses mesmos autores realizaram estudo em um modelo de CLP, no qual observaram que a administração de Agpi $\omega$-3 promoveu diminuição da produção do ânion superóxido das artérias dos ratos sépticos e elevação da produção de prostaglandinas. No presente estudo a suplementação com OP não foi capaz de minimizar a peroxidação lipídica.
Tem sido especulado que o efeito protetor do Agpi $\omega-3$ é efetivo somente em estado de leve imunossupressão, justamente ao contrário do que acontece na sepse (HUAl et al., 2018), justificando a ausência de melhora na função renal, pulmonar, imunológica e de lipoperoxidação verificada por este trabalho.

Acredita-se que os achados deste estudo não vão ao encontro de outros dados da literatura devido ao tempo de administração de OP, que foi menor (ou seja, apenas sete dias), o que talvez não tenha provocado modificação suficiente na razão $\omega-6: \omega-3$ na membrana das células. Outro fator pode ter sido a dose utilizada, que foi de $1 \mathrm{~g} / \mathrm{kg}$, a qual tem sido demonstrada ser eficiente para algumas doenças, como a cardiovascular (DELGADO-LISTA et al., 2012), mas não o foi para o modelo aqui utilizado de sepse, em particular, aguda. Vale destacar, contudo, que, apesar de não se ter encontrado diferenças significativas entre o controle e o suplementado, em termos histológicos ficou claramente demonstrado que $\mathrm{OP}$, neste intervalo de tempo e nesta dose, causou efeito positivo sobre o tecido pulmonar.

\section{CONSIDERAÇÕES FINAIS}

O estudo mostra que o OP administrado previamente à $C L P$, na dose e tempo empregados, não foi eficaz em minimizar os efeitos da sepse, nos animais estudados, quanto à taxa de mortalidade, à peroxidação lipídica e aos marcadores de funções renal e pulmonar.

\section{REFERÊNCIAS}

ALAVI, M. M. et al. Protocol adherence for severe Sepsis and septic shock Management in the Emergency Department; a clinical audit. Emergency, v. 5, n. 1, p. e16, 2017.

BAKER, E. J. et al. "Metabolism and functional effects of plant-derived omega-3 fatty acids in humans". Progress in Lipid Research, v. 64, p. 30-56, 2016.

BOISRAMÉ, H. J. et al. "Immunonutrition" has failed to improve peritonitis-induced septic shock in rodents. PLoS One, v. 11, p. e0147644, 2016.

CAMPOS, R. et al. N-acetylcysteine prevents pulmonary edema and acute kidney injury in rats with sepsis submitted to mechanical ventilation. Am. J. Physiol. Lung. Cell. Mol. Physiol. v.302, p.L640-L650, 2012.

CLARK, W. F. et al. Chronic Eftect of $\omega-3$ fatty Acids (fish Oil) in a rat 5/6 Renal Ablation Model. J. Am. Soc. Nephrol., v. 1, p. 1.343-1.353, 1991.

DELGADO-LISTA, J. et al. Long chain omega-3 fatty acids and cardiovascular disease: a systematic review. $\mathrm{Br} J$ Nutr., n. 107, Supl. 2:S201-13, jun. 2012. DOI: 10.1017/ S0007114512001596. 
DUVALL, M. G.; LEVY, B. D. “DHA - and EPA - derived resolvins, protectins and maresins in airway inflammation". European Journal of Pharmacology, v. 785, p. 144-155, 2016.

ERDOGAN, H. et al. Effect of fish oil supplementation on plasma oxidant/antioxidant status in rats. Prostaglandins Leukot. Essent. Fatty Acids, v. 71, p. 149-152, 2004.

GO, Y. M. et al. A key role for mitochondria in endothelial signaling by plasma cysteine/cystine redox potential. Free Radic. Biol. Med., v. 48, p. 275-283, 2010.

HUAI, S. C. et al. Correlation analysis of omega-3 fatty acids and mortality of sepsis and sepsis-induced ARDS in adults: data from previous randomized controlled trials. Nutrition Journal, v. 17, n. 57, p. 1-14, 2018.

JUEY-MING, S. et al. Fish Oil-Based Fat Emulsion Reduces Acute Kidney Injury and Inflammatory Response in Antibiotic-Treated Polymicrobial Septic Mice. Nutrients, v. 8, n. 3, p. 165, 2016. DOI: 10.3390/nu8030165.

KÖRNER, A. et al. Resolution of inflammation and sepsis survival are improved by dietary $\Omega-3$ fatty acids. Cell Death and Differentiation, v. 25, p. 421-431, 2018.

$\mathrm{LI}, \mathrm{X}$. et al. Fish oil-supplemented parenteral nutrition could alleviate acute lung injury, modulate immunity and reduce inflammation in rats with abdominal sepsis. Nutr. Res., v. 35, p. 784-791, 2015.

MANZANARES, W.; LANGLOIS, P. L.; HARDY, G. "Intravenous lipid emulsions in the critically ill: an update". Current Opinion in Critical Care, v. 22, p. 308-315, 2016.

MARANGONI, F. et al. Changes of n-3 and n- 6 fatty acids in plasma and circulating cells of normal subjects, after prolonged administration of 20:5 (EPA) and 22:6 (DHA) ethyl esters and prolonged washout. Biochim. Biophys. Acta., v. 1.210, p. 55-62, 1993.

MARTIN, J. M.; STAPLETON, R. D. Omega-3 fatty acids in critical illness. Nutr. Rev., v. 68, n. 9, p. 531-541, 2010.

MIYAJI, T. et al. Ethyl pyruvate decreases sepsis-induced acute renal failure and multiple organ damage in aged mice. Kidney International, v. 64, p. 1.620-1.631, 2003.

MOLFINO, A. et al. Omega-3 Polyunsaturated Fatty Acids in Critical Illness: Anti-Inflammatory, Proresolving, or Both? Oxidative Medicine and Cellular Longevity, v. 2.017, article ID 5987082, 6 p. 2017. Disponível em: https://doi. org/10.1155/2017/5987082.

NOUROOZ-ZADEH, J. Ferrous Ion Oxidation in Presence of Xylenol Orange for Detection of Lipid Hydroperoxides in Plasma. Methods Enzymol., v. 300, p. 58-62, 1999.

PRADELLI, L. et al. "N-3 fatty acid-enriched parenteral nutrition regimens in elective surgical and ICU patients: a meta-analysis". Critical Care, v. 16, p. R184, 2012.

SERHAN, C, N.; CHIANG, N. "Resolution phase lipid mediators of inflammation: agonists of resolution". Current Opinion in Pharmacology, v. 13, p. 632-640, 2013.

SERHAN, C. N. "Pro-resolving lipid mediators are leads for resolution physiology". Nature, v. 510, p. 510-592, 2014.
SINGER, P. et al. "Benefit of an enteral diet enriched with eicosapentaenoic acid and gamma-linolenic acid in ventilated patients with acute lung injury". Critical Care Medicine, v. 34, p. 1.033-1.038, 2006.

SPITE, M. et al. Resolvin D2 is a potent regulator of leukocytes and controls microbial sepsis. Nature, v. 461, p. 1.2871.291, 2009.

STRANDBERG, L. et al. Mice chronically fed high-fat diet have increased mortality and disturbed immune response in sepsis. PLoS One, v. 4, p. e7605, 2009.

SVAHN, S. L. et al. Dietary Omega-3 fatty acids increase survival and decrease bacterial load in mice subjected to Staphylococcus aureus-induced Sepsis. Infect Immun., v. 84, p. 1.205-1.213, 2016.

VIEIRA, R. P. et al. Creatine Supplementation exacerbates allergic lung inflamation and airway remodeling in mice. Am. J. Respir. Cell. Mol. Biol., v. 37, p. 660-667, 2007.

YANG, L. L. et al. Salvianolic acid A inhibits angiotensin II induced proliferation of human umbilical vein endothelial cells by attenuating the production of ROS. Acta Pharmacol. Sin., v. 33, p. 41-48, 2012.

YING-HUA, L. et al. Omega-3 Fatty Acid Intervention Suppresses Lipopolysaccharide-Induced Inflammation and Weight Loss in Mice. Mar. Drugs, v. 13, n. 2, p. 1.026-1.036, 2015. DOI: $10.3390 / \mathrm{md} 13021026$.

ZHAO, Y.; WANG, C. Effect of v-3 polyunsaturated fatty acid-supplemented parenteral nutrition on inflammatory and immune function in postoperative patients with gastrointestinal malignancy: A meta-analysis of randomized control trials in China. Medicine, v. 97, n. 16, p. e-0472, 2018. 